\title{
Misconception Analysis Based On Students Mental Model In Atom Structure Materials
}

\author{
Abdul Majid \\ Teaching Staff of Chemistry Education Study Program \\ University of Mulawarman Samarinda \\ Samarinda, Indonesia \\ abdul.majid@,fkip.unmul.ac.id
}

\author{
Suyono \\ Teaching Staff of the Department of Chemistry, Faculty of \\ Mathematics and Natural Sciences \\ Surabaya State University \\ Surabaya, Indonesia
}

\begin{abstract}
One of the causes of misconception in chemical studies is mental models. Mental models are students' initial abilities which consist of perception, understanding discourse, and imagination ability. This study aims: (1) to determine the level of student understanding in understanding the concept of atomic structure (2) to determine the profile of students' mental models (3) to determine the relationship between misconceptions and mental models of atomic structures. Determination of the sample was determined by purposive sampling technique totaling 34 students. The instrument of this study is a written test of mental models and misconceptions. Questions of mental models are divided into students 'perceptions, discourse comprehension questions, and questions of students' imagination abilities. Identification of the concept of understanding using CRI (Certainty of Response Index) is useful to determine students' level of trust. The results show that the number of students who experience misconceptions is more than the number of students who understand the concept and students who do not understand the concepts in atomic structure. The majority of students are at the level of perception level 4 , while understanding discourse and understanding the imagination of students in the medium category. The results of the cross tabulation prove that the mental level of the higher student model has a lower misconception.
\end{abstract}

Keywords-Misconception, Index Response Certainty, Mental Model, Cross Tabulation.

\section{INTRODUCTION}

Chemistry is one subject that is still considered difficult by high school students. One of the main causes is that in chemistry there are many abstract concepts. Mastery of abstract concepts has a higher level of difficulty than mastering concrete concepts, because understanding abstract concepts requires a stronger role of reasoning power to solve problems that cannot be observed directly. To overcome learning difficulties, students sometimes make their own interpretation of a concept they learn. But sometimes the results of interpretation of a concept created by students deviates from the concept agreed upon by experts. The emergence of this discrepancy has an impact on the emergence of errors in understanding better known as misconception [1].

One factor in the occurrence of misconceptions in students is the mental model they have. Mental models are ideas that represent the construction of imaginative understanding and visualization in the minds of students who they use to describe and explain phenomena. Misconceptions that occur due to this mental model are influenced by the influence of perceptions, everyday language interference, the abstract character of concepts studied by Abdul Majid [1]. That many misconceptions occur because learning materials that are considered abstract fail to be understood by students using the mental models they already have [11].

Atomic structure is one of the chemistry subject matter that is susceptible to cause misconceptions. One of the causes of this misconception in atomic structure can be due to the different mental models each student has. Students' misconceptions on the topic of atomic structure show that students do not have an atomic conception in accordance with what scientists understand because students form a false mental model of atoms. This misconception occurs because the definition and description of the atoms they think are less than perfect.

The atomic picture can be known by giving a mental model test to each student. One of the goals of this mental model test is to find out which atomic theory they master most and then equate the perception of atomic theory. Furthermore, it can be given a test in the form of questions about atomic structure in order to determine whether there is a misconception in students regarding the material of the atomic structure.

Based on the above background, there will be a research on misconception analysis based on students' mental models on atomic structure material.

\section{METHODS}

This type of research is qualitative research with preexperimental research methods. This research is called qualitative because the research data is descriptive and tends to use analysis with an inductive approach [2]. Sampling was done by purposive sampling technique. The research instrument used was a test in the form of misconceptions and mental model questions consisting of tests of perception, understanding of discourse, and students' imagination abilities. The data obtained is then analyzed.

\section{A. Misconception Analysis}

1) Identifying student misconceptions of Response Index (CRI) method. CRI has 6 levels of choice to determine the degree of certainty of students (degree of certainty. $a$ ) if the answer is guessed (totally guess answer), $b$ ) if the answer is almost guessed (almost guess answer), $c$ ) if the answer is doubtful (not sure), d) if the answer sure (sure), e) if the answer is almost certain (almost certain), and $f$ ) if the answer is certain (certain). [10] 
2) Percentage of Concept Understanding is calculated in percentages to find out the percentage of students in the category; misconception.

\section{B. Mental Model Profile}

1) Profile of students 'perceptions can be known from students' answers to perception test questions. Student responses to question items in Student Perception Detection Instruments related to atomic structure are calculated by percentage. Perception test consists of 7 multiple choice questions. In this test there is no wrong answer. All answers are given a score according to the perception ability of each afternoon. Although this test is in the form of multiple choices, 6 of the 7 questions are semi-closed questions. Perception test results are grouped into 4 levels of perception namely level 1 (atomic-Quantum atomic perception), level 2 (Quantum-Bohr atomic perception), level 3 (atomic perception of Quantum-Bohr-Particles), and level 4 (Particle atom perception).

2) Profile of Discourse Understanding is determined from the correct answer on the discourse comprehension test questions given a score of one (1), and for the wrong answer given a score of zero $(0)$. Then the total score is calculated for the correct answer and grouped into three categories, namely low, medium, and high categories, Arikunto. (c) Profile of Imagination Ability is determined by scoring on each correct answer (score 1). The scores of the correct answers are then summed and grouped into three categories of low, medium, and high [3].

\section{Misconception Relationships and Mental Models}

Cross tabulation analysis method is used to see the relationship between variables. Cross tabulation is a method that tabulates several different variables into a matrix whose results are presented in rows and columns. The cross tabulation conducted in this study uses the SPSS 16 program (Statistical Product and Service Solutions). The steps taken in the use of cross tabulation in this study are editing, coddling, entry, and tabulation.

\section{RESULT AND DISCUSSION}

\section{A. Misconception identification}

The concept of atomic structure in this study is divided into four (4) sub-concepts namely Atomic Skin, Electron Configuration, Orbital, and Quantum Numbers. Each of these sub concepts consists of 5 questions. Understanding this concept is divided into students who misconceptions and students who do not experience misconceptions. Students who do not experience misconception consist of students who understand the concept and students who do not understand the concept. At the atomic skin sub-concept, the average percentage of students who experienced misconceptions was $54 \%$, students who understood the concept $24 \%$, and students who did not understand the concept $21 \%$. Sub-concepts of atomic skin are sub-concepts with experienced misconceptions greater than the other three concepts.

This has the most misconceptions, namely number 1 , which is $65 \%$ (22 students). In this matter, students were asked to determine the valence skin and the number of valence electrons, but only $15 \%$ (5 students) understood the concept. In this case students have figured out how to make electrons in atomic skin, but they have not understood that what is used in arranging electrons in each skin is the atomic number or number of protons or the number of electrons not at atomic time or number of neutrons.

Students who do not understand the electron configuration sub-concept are sub-concepts with the average percentage of the least number of students experiencing misconceptions and students who do not understand the concept. This sub-concept becomes a sub-concept that is widely understood by students. The percentage of students who understand the electron configuration sub-concept lies in problem number 10 as many as 22 students. In this problem only $9 \%$ (3 students) experienced misconceptions and 24\% (8 students) did not understand the concept. The biggest misconception percentage in this sub-concept is in problem number 7 .

This problem determines the most stable electron configuration in the $\mathrm{Ag}$ element. The large percentage of students who understand the concept of the electron configuration sub-concept indicates that students have the ability to configure electrons, but some of these students experience misconceptions or do not even understand the concept of stable electron configurations.

Orbital sub-concepts become the second sub-concept with the largest percentage of students experiencing misconceptions. Problem number 11 is a problem with the highest percentage of misconception 56\% (19 students). This problem requires students to choose the right orbital definition, and it turns out that many students choose orbitals as spaces in atoms where electrons can be found. Student answers contradict the theory of Quantum Mechanics which states that the position of electrons in atoms cannot be determined with certainty. In this problem it can be seen that students misunderstand the concept. They assume that in orbitals, electrons must be found.

In the fourth sub-concept, namely the quantum number of students who have $48 \%$ misconceptions, students understand the concept $16 \%$, and students do not understand the concept of $33 \%$. This sub-concept is the sub-concept that is least understood by students and is the concept that most students do not understand. If you see the percentage of each question, the percentage of understanding the concept always ranks lowest in understanding the concept. This shows that there are still many students who do not understand the concept of quantum numbers.

Through the identification of misconceptions it can be concluded that there are still many students who experience misconceptions in the material of atomic structure. Some students understand concepts partially or not intact. This partial understanding that causes students to work on problems in accordance with the concepts they understand. As happened to the concept of atomic skin and electron configuration. Basically students know how to configure electrons, but their understanding of electron configurations is stable and the number of valence electrons is still lacking. Piaget in cognitive theory states that students who are still in the concrete stage will still be limited in constructing their knowledge, especially in abstract concepts. Students cannot easily generalize, abstract, and logically systematic thinking, at this stage, students' conceptions are incomplete or even misconstrued. According to Comins, students' incomplete 
reasoning is caused by incomplete information or data, as a result students draw conclusions incorrectly and this can lead to misconceptions in students.

\section{B. Analysis of Students Mental Models}

\section{1) Students Perception}

After obtaining the results of the study and grouping based on each level of perception. No students have the perception of Atomic Quantum Mechanics level, 1 student has Bohr-Quantum Atomic perception, 7 students have the Quantum-Bohr-Particle Atomic perception, and 26 students have Atomic Particle perception. Students with the perception of the Bohr Quantum Atom have a balanced perception ability between Quantum and Bohr. Based on the level of perception, it is known that the perception held by students is still low. The perception they have about atoms is still a mixed atomic model between Quantum, Bohr, and other concrete models. The number of students who are on the perception of particle level results in misconceptions in students.

\section{2) Discourse Understanding}

A total of 34 students took this test, 6 students included in the category of low discourse comprehension, 23 students entered the category of moderate discourse comprehension, and 5 students in the high category. It is seen that the majority of students have a moderate understanding of discourse. The number of students who are included in the understanding of high category discourse is only 5 people. This can be understood because in chemistry lessons new words will be found foreign to them, especially for those who have just studied chemistry in high school. For this reason, it is necessary to increase the understanding of discourse, because in the following chemical materials new terms will be found. Improved understanding of this discourse also serves to reduce the occurrence of misconceptions in students.

3) Imagination ability

This test is used to measure the extent to which students can understand the atomic picture visually. The imagination ability test results are categorized as students based on low, medium, or high students' imagination abilities. As many as 10 students included in the category of low imagination ability, 19 students in the medium category, and 5 students in the high category. As with discourse understanding, the majority of students have moderate imagination. Students who have high imagination ability are very few, so it is feared that it will become an obstacle for students in visualizing atomic structure. The role of the teacher is needed to improve students' imagination abilities.

\section{Relationship between Student Misconceptions and Mental Models.}

1) Relationship between Misconception and Perception

The first mental model is perception. The number of students who experience misconceptions with a low, medium, and high category if connected with the level of perception. Based on the graph above it can be seen that the relationship between misconception and the level of student perception is inversely proportional. At the level of perception, researchers categorize that Particle level perception is the lowest level of perception students have. This is because at this level students have not found a concrete form of atom. Meanwhile the level of Quantum

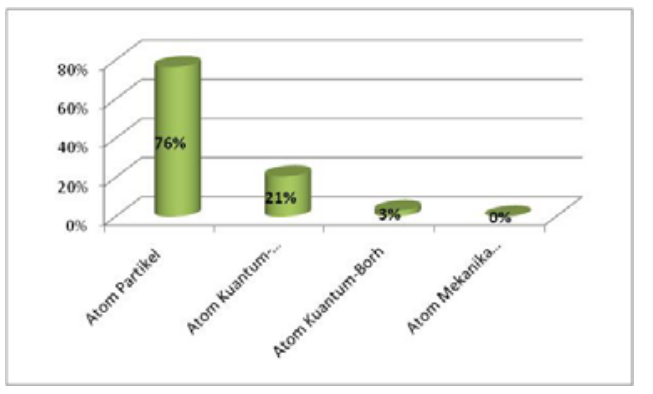

Fig. 1. Relationship between Misconception and Student Perception Level.

mechanics is the highest level of perception of the level of students' perceptions because at this level students really understand the atom based on the theory of quantum mechanics. From the graph shown above, it can be concluded that the lower the level of student perception, the greater the chance of misconception.

In the graph, the percentage of students who experienced the biggest misconceptions were students with the lowest perception level, namely the perception of particle level with the number of students who experienced misconceptions as many as 26 students. While the number of students who experienced misconceptions on the perception of Quantum-Bohr level was 1 student and the perception of Quantum-Bohr-Particle level was 7 students.

If analyzed through the problem of understanding understanding concepts, then problem number 11 has proven this theory. The percentage of students who experienced misconceptions in this problem could be due to the perception of the student's orbitals not in accordance with the existing theory.

In addition, if viewed from the results of misconceptions analysis research, the sub concepts of quantum numbers also reinforce the theory. In the misconception detection problem, the subconceptions of quantum numbers occur misconceptions. This can happen because the perceptions that students have are at the particle level and perceptual profile research shows that none of the students have perceptions of level 1 (Quantum models). So it is not surprising that in the subconcept of quantum numbers many students experience misconceptions or do not even understand the concept.

2) Relationship between Misconception and Discourse Understanding

Students who have an understanding of discourse while the majority have a moderate burden of misconception. Students who have an understanding of high category discourse all enter into students who experience moderate misconceptions. The following graph illustrates the relationship between misconception and the level of understanding of discourse.

The graph above shows that the number of students with low discourse comprehension categories tend to experience higher misconceptions, as well as for students who have 
high discourse understanding, the chances of misconceptions will be lower. Although the difference in numbers between students with low-class discourse understanding and students with high-category discourse understanding is very small, the graph reinforces the theory that understanding students' discourse can determine the chances of misconceptions. The higher the students' understanding, the lower the chance of misconceptions.

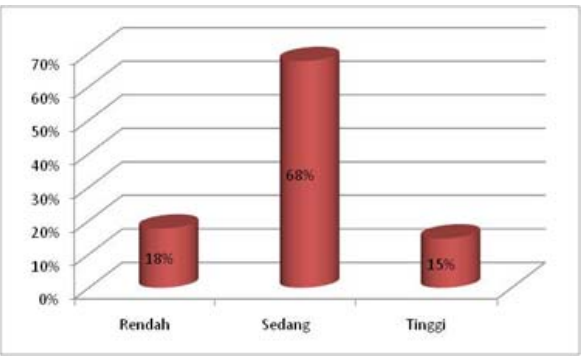

Fig. 2. Relationship between Misconception and Student's Discourse Understanding Level.

\section{Ability}

3) Relationship between Misconception and Imagination

The ability of students who have been categorized into low, medium, and high categories is then analyzed using cross tabulation. The results of the analysis show that students with high imagination ability tend to have low misconceptions. This is evidenced by the number of students, as many as 5 students. Students with low imagination ability are 10 people, and misconceptions are currently 19 people.

Students with medium imagination ability, enter into the medium category misconception as well. The relationship between misconception and the level of imagination of students is illustrated in the following diagram.

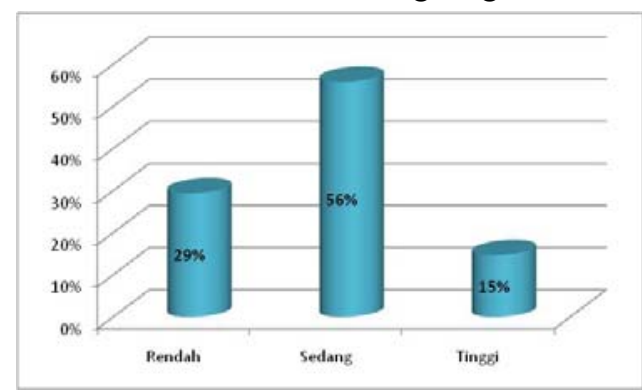

Fig. 3. Relationship between Student's Imagination Ability and Misconception.

Analysis of misconception relationships and mental models in cross tabulation is known that mental models which consist of perception, understanding discourse, and imagination ability are very influential on the occurrence of misconceptions in students. Teachers should know in advance the extent to which students understand the material to be taught. After that, a learning model can be determined that can help students to develop their mental models to minimize misconceptions.

The selection of learning models tends to be difficult for the class with the number of students who are many and heterogeneous, but these constraints can be reduced by equating students' perceptions of the material to be taught. After knowing the extent to which students understand the material being taught, it can determine the appropriate learning model. But if in the delivery of perceptions of many students who are still misconcepted or do not understand the concept, then the teacher must justify the wrong concepts. In addition to equating perception, the selection of learning models must also be able to develop students' imagination abilities so that concepts that are considered abstract can be more easily understood.

The teacher must be able to explain clearly the meaning of chemical terms while teaching the material, because many students experience misconceptions about chemical terms. This is related to how students understand the discourse they are reading, especially for some terms in chemistry that they have just discovered during learning.

\section{CONCLUSIONS}

Percentage of students' misconceptions on atomic skin subconceptions was $54 \%, 34 \%$ electron configuration subconcepts, $50 \%$ orbital subconcepts, and $48 \%$ quantum numbers. Generally students have a perception of particle level, while in understanding the discourse the majority of students are in the medium category, and the students' imagination ability is in the medium category. The higher the mental model students have, the lower the likelihood of misconceptions in these students.

\section{REFERENCES}

[1] Abdul Majid, Binar Kurnia Prahani, Usman, M. Amir, Suyono (2018) Misconception Identification Of Buffer Solution Concept And Students' Learning Style, IOSR Journal of Research \& Method in Education Volume 8 Issue 2 Ver. $\mathrm{V}$ page 4754http://www.iosrjournals.org/iosr-jrme/papers/Vol-8\%20Issue2/Version-5/G0802054754.pdf

[2] Sugiyono. (2013). Educational Research Methods. Bandung: Alfabeta

[3] Arikunto S., (1992). Research Management. Jakarta: PT Rineka Cipta

[4] Abdul Majid and Binar Kurnia Prahani (2017) Analyze Students' Learning Outcomes Based on Mental Models of Atomic Structure. IOSR Journal of Research \& Method in Education (IOSR-JRME) Volume 7, Issue 1 Ver. I (Jan. - Feb. 2017), PP 120-124 www.iosrjournals.org

[5] Andari, M. (2012) Analysis of the Profile of the Mental Model of High School Students and the Influencing Factors on the Topic of Buffer Solution Solution. Thesis published. Bandung: Indonesian Education University.

[6] Laliyo, Lukman Abdul Rauf. (2013) "Student mental models in understanding changes in the form of substances", Journal of Research and Education, Volume 8 No. 1, March 2013.

[7] Sofyan, A., (1993). Communication Psychology, Bandung: Teenagers Rosdakarya

[8] Verawahyuni, Helda., (2014). Development of Detection Instrument for Chemical Misconception Causes Based on Mental Models on Atomic Structure Concepts, UNESA; Surabaya.

[9] Wang, C.Y. (2007). The Relationship Between Formal Thinking Ability and Visual-Spatial Intelligence with the Ability to Describe Molecular Forms of Students of the Gorontalo Model XI Class of the Academic Year 2010/2011. Entropy Journal. Vol 08, No 01, Pp 551561.

[10] Hasan, S., et al. (1999). Misconceptions and the Certainty of ResponseIndex (CRI). Phys. Educ. 34 (5)

Horton, C., (2004). Students Preconceptions and Misconceptions. Arizona State University. Worcester 01602 